\title{
APPLICATION OF ALUMINUM AND ALUMINUM ALLOYS IN ENGINEERING
}

UDC: $629.3: 621.89$

Review paper

https://doi.org/10.18485/aeletters.2018.3.2.2

\author{
Blaza Stojanovic ${ }^{1}$, Milan Bukvic ${ }^{1}$, Igor Epler ${ }^{2}$ \\ ${ }^{1}$ University of Kragujevac, Faculty of Engineering, Sestre Janjic 6, 34000 Kragujevac, Serbia \\ ${ }^{2}$ University of Defence, Military Academy, Pavla Jurišića Šturma 33, 11000 Belgrade, Serbia
}

\begin{abstract}
:
The paper deals with the considerations related to the basic properties and application of primarily aluminum alloys and composite materials for different purposes with the focus on the automotive industry. Through the description of the basic characteristics of aluminum alloys, the starting points for their application in different technical systems are given. On the other hand, the advantages and disadvantages of the use of certain aluminum alloys, along with the guidance and compounds and elements whose use is further enhanced and enriched by aluminum alloys, are predominantly presented. The application of aluminum alloys in the automotive industry, as well as the particular types of aluminum based materials used for individual aggregates and circuits of motor vehicles, as well as their behaviour in different operating modes are imposed as a key chapter of the work. Ultimately, the advantages that are primarily achieved with the vehicle are obtained by the use of aluminum alloys and composites, with the conclusion that there is still space in the field, further improvement of the characteristics of aluminum alloys, and in the field of expansion of the diapason of their application.
\end{abstract}

\section{ARTICLE HISTORY}

Received: 13.03.2018.

Accepted: 24.04.2018.

Available: 30.06.2018.

\section{KEYWORDS}

aluminum, alloy, composite, motor vehicle, improvement

\section{INTRODUCTION}

Over the past decade significant progress has been made in the technological structures of materials used in modern vehicles. Safety, emission control of harmful combustion products and comfort impose the imperative for the development and production of the next generation of vehicles, with simultaneous demands for reducing the mass of the vehicle. Although some improvements have been made in the field of construction of motor vehicles, demand for automotive structures is still high, which will include increasingly lighter materials, which requires further development and research in this field.

Modern aluminum alloys due to their high power-to-weight ratio, low cost and high wear resistance have been widely used and used in many structural components, both in the aviation and automotive industries. Also, simple and economical methods for making most aluminum alloys are essential for further expansion of their application. The reinforcement and improvement of the base alloy in the form of aluminum compounds, silicon carbide, graphite, powdered compounds and others can easily be incorporated into the alloy material of aluminum alloy using cheap and widely available casting and mixing methods. This paper presents an overview of the mechanical and tribological properties of aluminum and its alloys, as well as their application for the production of various components of technical systems, and above all motor vehicles.

Among the most effective ways of achieving improvement in the properties of aluminum alloys is the creation of hybrid composites with two or more types of improvements. By adding, for example, ceramic reinforcements, the mechanical properties of the basic alloy are improving, but in 
this case the problem is increasing the material's brittleness. In order to solve this problem, graphite is added to composite materials already reinforced with ceramic material. The presence of graphite reduces the mechanical properties of the properties (hardness decreases), but tribological properties are improved [1,2].

\section{CHARACTERISTICS OF ALUMINUM AND ALUMINUM}

In general, composite materials are made of a casting of basic material, as the element with the highest percentage weight fraction compared to other components and other elements and compounds in order to strengthen the basic material in order to improve the properties. Compared to other metal composites, aluminum and its alloys are widespread. Aluminum and its alloys allow the use of various reinforcement and improvement materials. The main advantage of composite materials with aluminum as a base in comparison to materials without reinforcement are [3]:

$>$ greater strength,

$>$ greater stiffness,

$>$ reduced density (weight),

$>$ improved properties at high temperatures,

$>$ controlled coefficient of thermal expansion,

$>$ controlled heating of materials,

$>$ improved and adaptable electrical conductivity,

$>$ improved resistance to abrasion and wear,

$>$ controlled weight (especially for movements like ICE pistons),

$>$ improved depreciation ability.

But aluminum alloys have certain disadvantages such as high coefficient of thermal expansion and inadequate tribological characteristics. Higher stiffness and toughness, fatigue resistance, as well as the improvement of tribological characteristics, are obtained by adding material for strengthening and improving and thus modeling certain aluminum composites. As materials for improvement are distinguished $\mathrm{SiC}, \mathrm{Al} 2 \mathrm{O} 3$ and graphite $[4,5]$.

The effects of SiC and graphite on tribological and mechanical properties are different. By increasing the weight or volume of $\mathrm{SiC}$ and $\mathrm{Al} 2 \mathrm{O} 3$, an improvement in mechanical properties is obtained, while the increase in weight or bulk density of graphite improves the tribological properties of the given composite material. Optimal tribological and mechanical properties are obtained through a combination of the percentage fraction and modification of these two constituent materials.

Due to its favorable characteristics, the average use of aluminum, especially in the automotive industry in Europe, has increased significantly. A study by the European Association of Aluminum shows that the amount of aluminum used in car production in Europe almost tripled between 1990 and 2002. In 2012, it reached even an increase from $50 \mathrm{~kg}$ to $140 \mathrm{~kg}$. The mentioned Association predicts an increase in average consumption of aluminum for cars up to $160 \mathrm{~kg}$ by 2020 and up to $180 \mathrm{~kg}$ (Fig.1) [5].

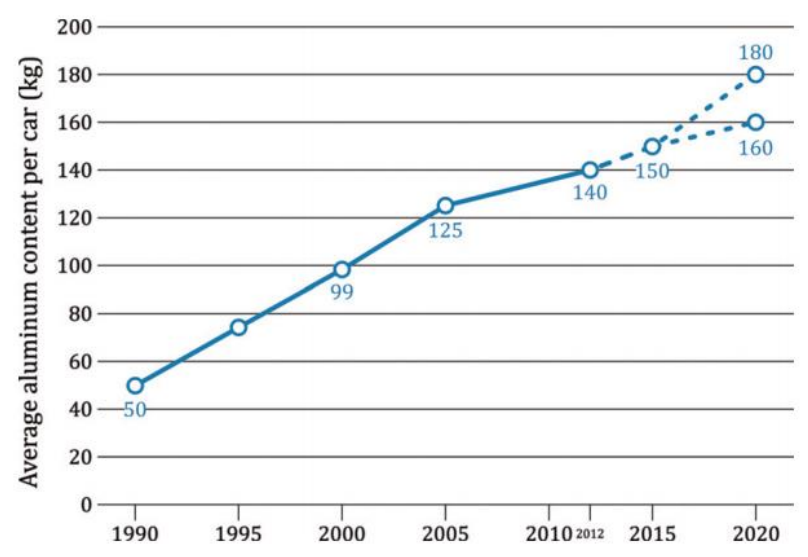

Fig. 1. Change in the average share of aluminum per produced vehicle in Europe [6]

On the other hand, the use of high-quality aluminum alloys ensures the benefits of maintaining technical systems, the application of aggregate principles when replacing certain important assemblies and aggregates, whose reliability and reliability directly affect the integrity of the entire complex technical system such as a motor vehicle, and in particular the use of advanced concepts of vehicle maintenance, such as the LEAN maintenance concept. This concept includes primarily: shortening maintenance time, shortening the vehicle's "in failure" time, increasing the vehicle availability ratio, and also the efficiency during vehicle operation [7].

Using advanced materials such as aluminum alloys it is possible to predict their behavior in real technical systems using appropriate simulation tools and software packages (ADVISOR, PSAT, RCF method), all in order to obtain the best characteristics of future modern vehicles and early detection of possible defects, before finishing testing and beginning of the serial production of vehicles [8].

Aluminum alloys, as well as other modern materials used in vehicles of the future, such as 
hybrid and electric vehicles, show an extraordinary tendency to use particularly modern recycling techniques and techniques in order to maximize the amount of seamless, rare, expensive and scarce materials reused and re-used to create new vehicle models, but also other technical systems. This is above all possible by the conquest of processes by which the compounds and alloys based on aluminum are relatively easy to disintegrate and obtain relatively pure elements and compounds for the subsequent production cycles $[9,10]$.

\section{APPLICATION OF ALUMINUM AND ALUMINUM LEADS IN DIFFERENT STRUCTURES}

Aluminum alloys for production, in particular the bodywork of motor vehicles, have only recently been used $[11,12]$. However, in a very short time, this type of material has gained very high popularity and presence in a large number of motor vehicle manufacturers, primarily because of its low mass and because it practically does not exhibit a tendency to corrosion. In addition to the vehicle body itself, certain parts of the ICE, as well as other power units (electric motors, etc.) are made of these alloys, as well as individual assemblies and parts of other systems on vehicles. One of the major shortcomings in the application of aluminum and its alloys is the difficult and demanding process of welding certain elements, but also its tendency to produce increased vibrations and noise. In order to reduce noise and vibrations, vehicle manufacturers primarily use insulating materials of high performance, which ultimately affect the increase in vehicle prices Fig.2 [13].

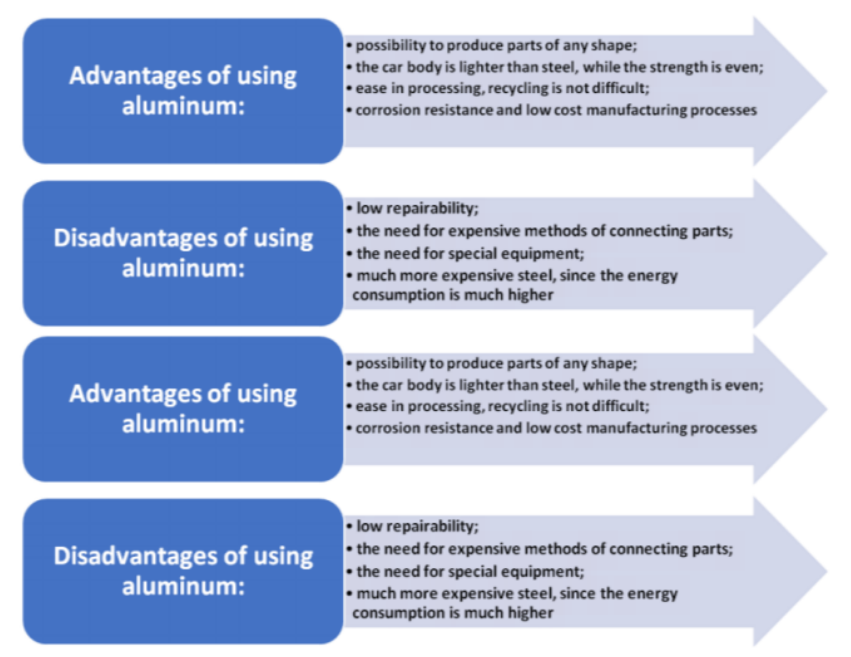

Fig. 2. Advantages and disadvantages of using aluminum in the automotive industry [3]
Aluminum bodywork has already reached mass production and use in motor vehicles, although mostly on more expensive vehicle models. However, the reduction of the mass of the vehicle continues, moving to a higher level, with the aim of increasing efficiency and reducing emissions of harmful combustion products during the exploitation of the vehicle. Aluminum alloys are now used not only for the bodywork of the vehicle, but also for parts of the vehicle's steering and restraint system. Physical and mechanical properties impose special requirements before the required repair and maintenance procedures for those vehicle assemblies.

Low density aluminum alloys, high workability, casting and forging properties and fatigue resistance up to $30 \%$ less compared to cast iron, as well as high thermal conductivity at the level of 125 to $146 \mathrm{~W} / \mathrm{m}$, makes them the basic materials for making engine pistons [14].

The problem of improving, improving and producing different types of aluminum alloys is present in different countries $[15,16]$. Like the application of pure aluminum, the main goal is to achieve the highest hardness, durability, corrosion resistance, plasticity, and other properties when considering the application of aluminum alloys in the automotive industry, which depends on the specific application of aluminum alloys for certain parts and vehicle assemblies. Different methods and techniques need to be applied to this end.

During the production of aluminum alloys, modifications are widely applied, both in the application of connective elements, as well as in the casting itself, using various additives. Among the elements used as additives are titanium and vanadium, which form the refractory metal alloys TiAl3 and VAI6, and ultrafine particles of oxides, carbides, borides and other non-metallic substances. Another type of modifier is surface layers and coatings that positively influence the structure of aluminum alloys, most of which are basically based on the chemical elements $\mathrm{Li}, \mathrm{Na}, \mathrm{K}$, $\mathrm{Rb}$ and $\mathrm{Cs}$, as well as sulfur and phosphorus. At the same time, numerous studies have shown the high efficiency of complex modifiers [14].

Efficient grinding of aluminum alloys is possible thanks to the addition of fine-spaced aluminum titanium-boron (AITiB) and aluminum-titaniumcarbon (AITiC) crystals into the casting of various alloys of aluminum alloys. Adding these compounds substantially improves mechanical properties and reduces their porosity in exposure to certain gaseous products. 
Different constructors are [17] in order to improve the structure, mechanical properties and convenience of maintenance, lower porosity, and on the basis of laboratory and simulation studies have come up with proposals of various compounds that would improve the properties of aluminum alloys. The aforementioned compounds and elements for improving the properties of the above alloys are overloaded with sodium carbonate, sulfur, purified silicon carbide and electrolytic titanium $[18,19]$.

The basic problem that many manufacturers of vehicle materials are facing is getting cheaper raw materials in the form of aluminum alloys, where the more efficient solution is found in their recycling. In the literature [19], an increase in the quality of aluminum alloys obtained by recycling up to $100 \%$ in relation to the same alloys obtained by primary production has been proven, which has led to the construction of significant installations for this type of recycling. Developed complexes have low costs, do not complicate the production of aluminum alloys, reduce emissions of harmful substances into the environment and improve working and hygienic conditions in cast aluminum alloys, while reducing the need for additives to improve alloy properties and up to $15 \%$ [20].

\section{APPLICATION OF ALUMINUM AND ALUMINUM LEADS IN MOTOR VEHICLES}

Aluminum composites of wide application relate primarily to the spectrum of highperformance lightweight aluminum alloy classes. The properties of aluminum composites show a tendency of light adaptability to the requirements of various industrial applications according to the appropriate combination of base alloys, certain improvements and processing modes [12,21].

The main advantages of aluminum alloys compared to conventional steel materials for the production of parts and vehicle assemblies are the following: higher vehicle power obtained by a lower mass of the vehicle, improved rigidity, reduced density (weight), improved properties at high temperatures, controlled thermal expansion coefficient, individual assemblies, improved and customized electrical performance, improved wear resistance and better noise attenuation [12].

Granular aluminum composite materials, which are used in the automotive industry, can reduce the weight of the car and improve a wide range of its performance, and can reduce oil consumption, reduce environmental pollution, and prolong the lifetime and / or exploitation of the vehicle. Compared with cast iron and steel structures, with aluminum alloy A359 with additional $20 \%$ SiC compounds, brake discs have a lower weight by 50 to $60 \%$, the weight of which is $5.4 \mathrm{~kg}$ in the case of steel, compared to only $2,5 \mathrm{~kg}$ when creating discs of identical dimensions of a total of 2,5 kg. Testing a vehicle in real-world conditions, with a radius of $5000 \mathrm{~km}$, it has been shown that the composite disc of aluminum alloy brakes provide significantly lower noise levels, as better removal of topolite from contact surfaces (cast iron and steel construction is 5-7 times heavier than construction from aluminum alloy [17].

For example, the company German Knorr Bremse AG developed a high-speed disk brake for conventional ICE vehicles, with a $20 \%$ weight reduction, using the Duralcan composite SiCp/AISi7Mg. On the other hand, the Kolbenschmidt company used composite brakes made of $20-30 \%$ SiCp/Al-Si for the Volkswagen Lupo - 3L TDI, and in the exploitation it achieved exceptional results by several criteria. Brakes for braking approximate characteristics were applied on vehicles Toyota RAV-4 EV, Plymouth prowler, Ford prodigy, Lotus Elise etc. Japanese automobile corporation Toyota applied composite materials based on aluminum labeled 2 ZZ - GEE to produce engine pistons, piston rings of the ICE, as well as a disc brake. At the same time, TiB2/Ti composite material for the production of exhaust valves of the engine was used on the Toyota Altezza vehicle, using fine-grained materials with a high concentration of aluminum instead of steel $21-4 \mathrm{~N}$. On the other hand, the high cost of particles of improved aluminum composites limit their mass production and application in transport means [17].

The primary processes for the production of aluminum alloys in industry can be classified into two basic groups shown in the Fig. 3 .

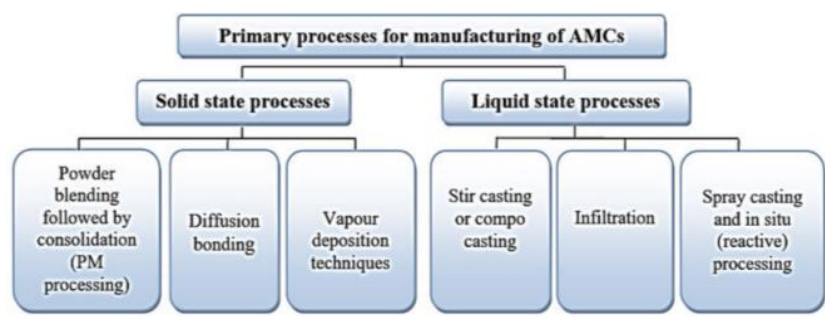

Fig. 3. Primary processes of production of aluminum alloys [3]

The choice of treatment types of aluminum alloys depends on many factors that include the type and level of the reinforcement of the alloy 
and the desired degree of integration of the microstructure.

The engine blocks of aluminum-based alloys and their alloys typically require cast iron castings, or special types of steel, because aluminum shows poor performance during wear. The automotive giant Porsche uses metal cylinder-shaped composites to integrate porous silicone material in a molded aluminum engine block, to a Honda manufacturer using a similar method involving aluminum and carbon fibers into the microparticles that exist in cast aluminum alloys [22]. This practice improves the wear characteristics and efficient cooling of steel-based elements.

At the University of Wisconsin in Milwaukee, pistons and cylinder walls of the ICE are developed on the basis of aluminum alloys containing dispersed graphite particles that provide good lubrication [23]. Aluminum containing graphite has a lower friction coefficient and lower wear rates, but does not cause the risk of limiting lubrication. The said aluminum alloys are heated by a centrifugation process during which the graphite particles are kept near the inner periphery where their presence is most needed to provide reliable lubrication $[23,24]$. Pistons and cylinders made on the basis of aluminum-graphite alloys have been tested in engines powered by petroleum gas, as well as in diesel engines, especially sports vehicles, resulting in reduced friction coefficient and wear rate of the said materials. In this case, the friction coefficient of the Al-graphite composites is about 0,2 lower than the graphite-free Al-codons [23]. The use of these cylinder-shaped materials in lightweight aluminum engine blocks allows the engines to reach operating temperatures faster, providing exceptional wear resistance, reduced emissions during cold start and naturally reduced weight [25].

Copper bearings, currently used extensively in main crankshaft supports, can be successfully replaced with aluminum composites containing graphite particles $[23,26]$. Graphite is non-toxic, and its use in aluminum alloys significantly reduces the weight of the bearings, also improving the characteristics during wear, as the deformation of graphite particles results in the formation of a continuous graphite film, which ensures selfdegradation of the components, which allows the extended lifetime of the component. These materials can be used for almost all ICE bearings. Such functional reinforced aluminum-graphitebased bearings are produced in one step as centrifugal casting of a metal graphite suspension (Fig.4).

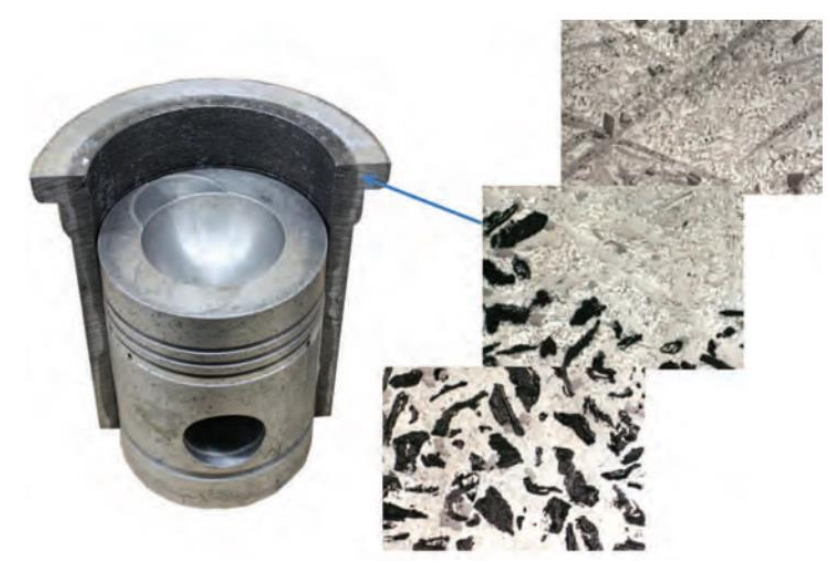

Fig. 4. Primary production processes of aluminum alloys [27]

On the other hand, with the emergence of nanostructured materials, new materials with exceptional properties were not expected for monolithic alloys or composites, but containing them containing reinforcements on a micron scale. In the example [28], which includes only $10 \%$ of $50 \mathrm{~nm}$ aluminum oxide (Al2O3) particles in the total aluminum alloy, the strength of the material up to 515MPa was increased using a powder metallurgy process. This is 15 times stronger than the basic alloy, six times stronger than the base alloy containing 46\% 29-mm Al2O3, and more than 1,5 times stronger than the stainless steel AISI 304. However, however, problems are also present, first of all related to the complexity of technology. Fig.5 shows typical microstructure alloys of cast aluminum 206 reinforced with $47 \mathrm{~nm}$ of alumina particles synthesized at the aforementioned University of Wisconsin with an illustration of equipment used to synthesize a composite [29].

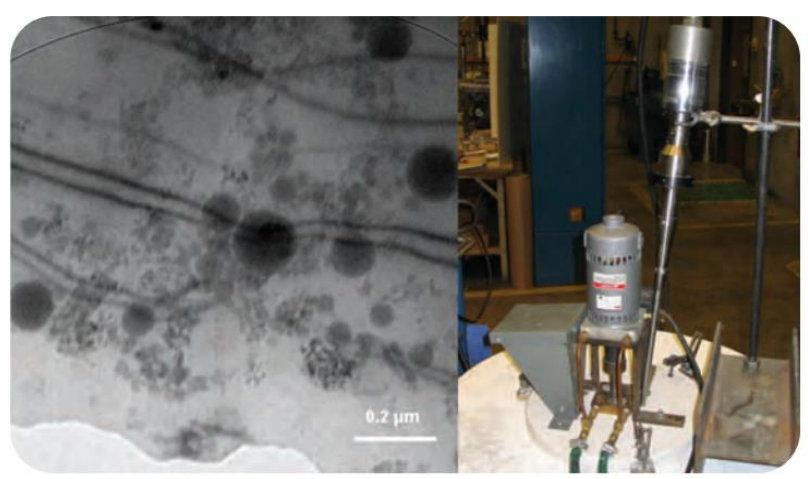

Fig. 5. Microstructure of cast aluminum alloy 206 reinforced with 47 nanometer alumina [29]

For components that are not exposed to extreme loads, cost reduction and weight reduction can be achieved by using less quality raw materials such as waste products from thermal 
power plants (eg aluminum, magnesium, lead and zinc materials). Replacement of components such as low-pressure pumps in the ICE, power transmission chains, alternator housing, gearbox housing, valve caps and suction collectors (Fig.6) with alloy wheels based on aluminum can significantly reduce production and maintenance costs, such as and the mass of the vehicle and thus contribute to reducing the emissions of harmful combustion products and energy saving $[30,31]$.

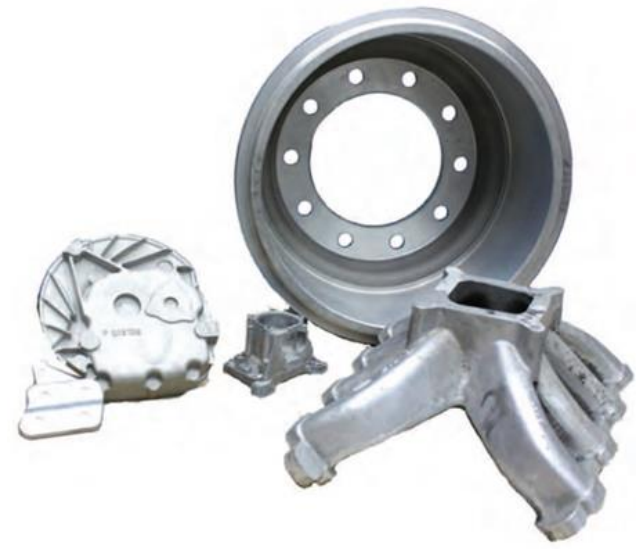

Fig. 6. Components of vehicles made on the basis of aluminum and magnesium alloys developed at the University of Wisconsin [30]

The strength and toughness of the chassis can affect the performance of the vehicle, and it is also important to ensure the safety and security of passengers during traffic accidents. Developed materials with hollow ceramic microspheres as constituents of metal alloys result in a product obtained capable of absorbing large amounts of energy per unit of weight after impact (accidents) compared to monolithic alloys. Such revolutionary aluminum-based materials (Fig.7) can be used for reinforcement box or frame of the vehicle, both in terms of revolving torsional stiffness, as well as in terms of improved vehicle dynamics and increased energy absorption during vehicle impact $[32,33]$.

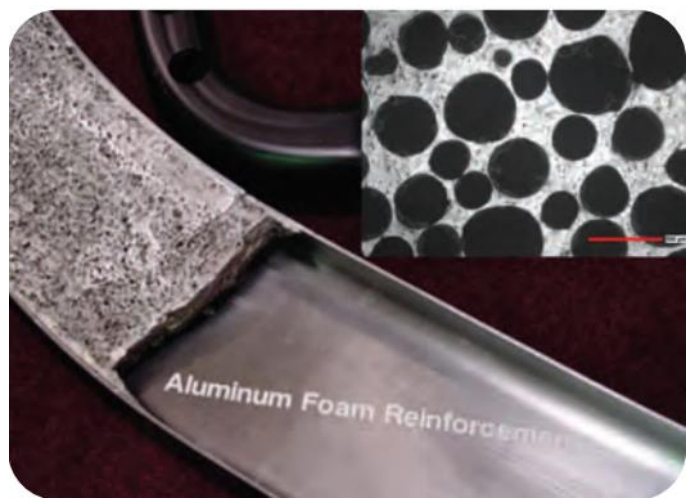

Fig. 7. Material with hollow ceramic microspheres of aluminum alloys [3]

\section{BENEFITS AND IMPROVEMENTS PROVIDED BY APPLICATION OF ALUMINUM AND ALUMINUM ALLOYS}

When considering advantages and disadvantages of particular materials, it is of utmost importance to understand the mechanical behavior in various dynamic systems, especially in complex systems such as motor vehicles. For example, it has been experimentally shown that the mechanical properties of the Al2024/Al2O3 composite such as the durability and the final tensile strength of the composite increase with increasing the volume fraction of the $\mathrm{Al} 2 \mathrm{O} 3$ particles of the vehicle [34]. In addition, the strength of the composite has been observed to increase while the final tensile strength and tensile strength are reduced by increasing the percentage of the volume of the ceramic material. In the application of the Al-TiB2 alloy, the composite obtained by mixing intensively during the casting process has been found to have a tensile strength and load transfer capacity of two times that of a conventional aluminum alloy, but the stretching ability exhibits a lower value [35]. Some authors [36] investigated the mechanical and corrosion behavior of the hybrid composite aluminum reinforced $\mathrm{SiC}$ obtained on the basis of bamboo. It has been found that the final values of the tensile strength, hardness and durability of the composite are reduced with an increase in the percentage of the weight fraction of the bamboo leaf powder, while the toughness and fracture resistance of the hybrid composite have been significantly improved. In addition, the corrosion resistance of such a hybrid composite was more pronounced in the base solution compared to the acid solution. By studying the mechanical and wear properties of the AlSi18CuNi/Al2O3 aluminum composite, it has been found that composite materials with a mass fraction of $2 \% \mathrm{Al} 2 \mathrm{O} 3$ have a tensile strength and hardness of $505 \mathrm{MPa}$ and $123 \mathrm{Hv}$ greater than unburned aluminum alloys. And the abrasion resistance is also increased in the case of said aluminum composite [37].

By producing an aluminum composite A356.1 strengthened $\mathrm{MgO}$ nanoparticle, it has been found that hardness and resistance to high pressures is higher compared to conventional aluminum alloys [38]. Experimental methods have found that hardness has assessed the hardness and resistance to impacts of Al composites (A356)/SiC markedly higher compared to pure alloy [39]. By studying 
the tensile strength of the reinforced Al composite (2024) nanoparticles Al2O3 using a three-step casting method, it was found that the strength and tensile strength of said enriched composite is significantly superior to the classical Al alloy [40].

By attaining the Al (6061-T6) / B4C composite and testing its mechanical properties, it was found that the hardness (Fig.8a) and the tensile strength (Fig.8b) of the composites linearly increase with an increase in the percentage of particles B4C in the total mass [41].

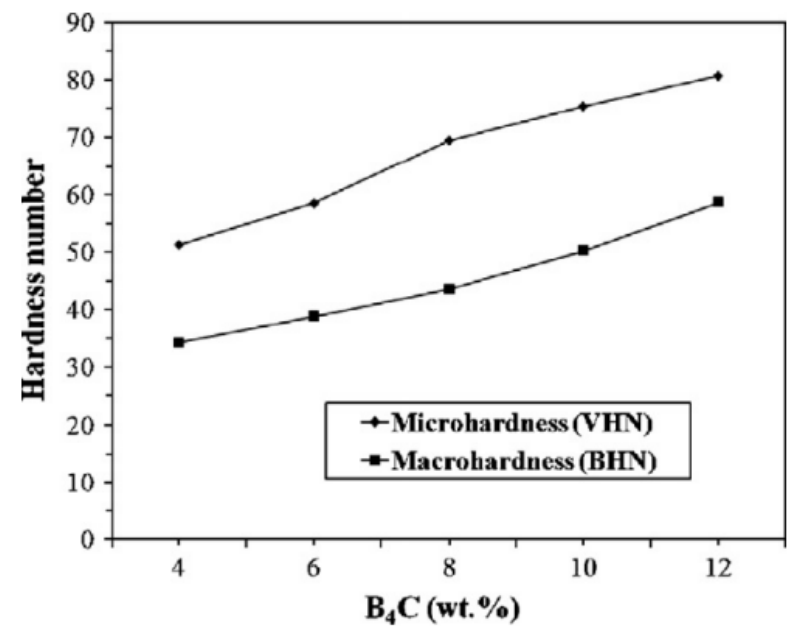

Fig. 8a. Change in the hardness of the alloy with the percentage of the B4C fraction [41]

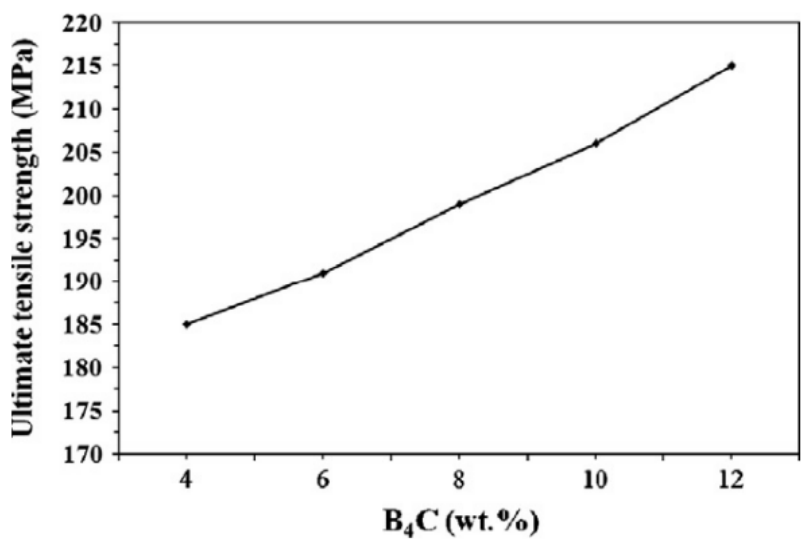

Fig. 8b. Change in ultimate tearing with a percentage of B4C fraction [41]

Great importance are the advantages of using aluminum alloys and composites in terms of tribological characteristics. The tribological behavior of aluminum composites has been the subject of more research due to their application in bearings, racing (brushes) of electric machines (electric motors and generators), various contact strips, conductors, etc. A study of the behavior of high-temperature dry slip wear of the $\mathrm{Al}$ (A356)/SiC, Al (A356)/(SiC+graphite) and Al (6061)/Al2O3 composites shows that the addition of ceramic particles improves the resistance of composites at a higher temperature compared to pure alloy, which in this respect SiC shows higher efficiency than Al2O3. Of the above three aluminum composites, the first shows a higher wear resistance than the other two composite materials at higher operating temperature temperatures [42].

From the aspect of wear, it was found that the aluminum composite has a lower tendency to wear than pure $\mathrm{Al}$ alloys, with $\mathrm{Al}$ (A356)-10\% TiC exhibiting the highest wear resistance. Experimental studies of the behavior of aluminum composites Al-Tib and Al-4,5\% Cu-Tib2 developed by mixing method during casting revealed that the wear losses of both composites are reduced by increasing the volume of the Tib2 fraction. Fig.9 shows that the loss of material due to wear increases with the flow of certain assemblies, but it is much less pronounced in enriched composites, than in the case of the classic Al alloy. Also, the wear resistance of the composite Al-Tib2 was greater than the composite material $\mathrm{Al}-4,5 \% \mathrm{Cu}$ Tib2 [43].

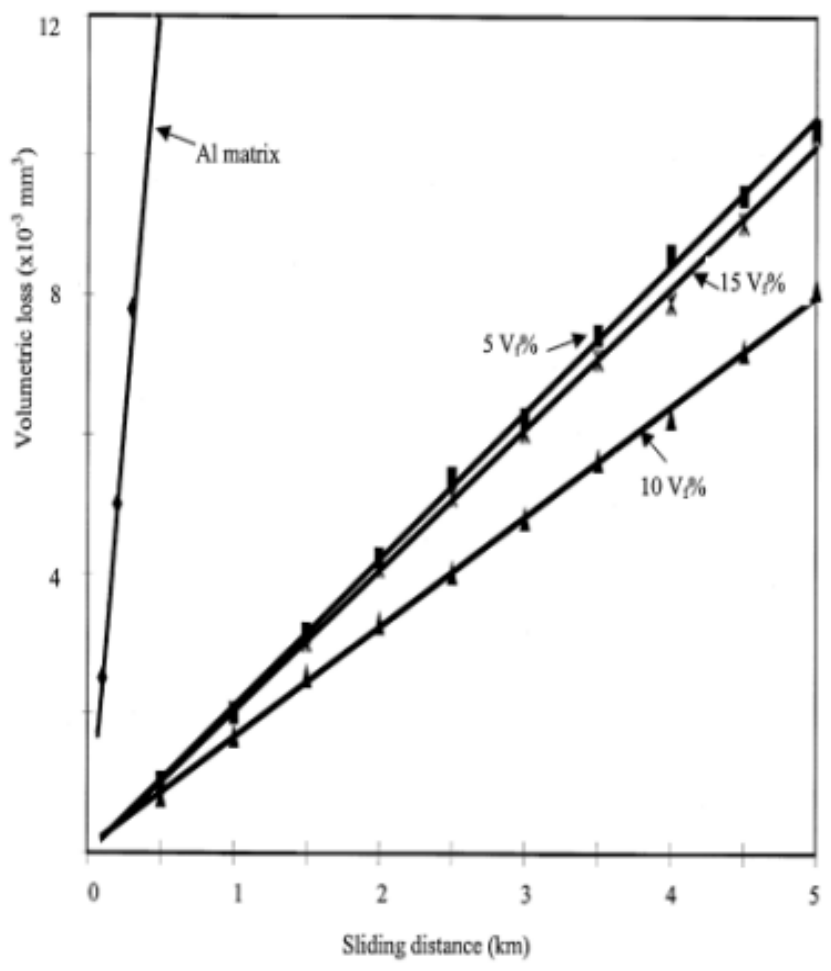

Fig. 9. Dependence of volume loss of material during exploitation [43]

By investigating the tribological behavior of the samples made from the composite $\mathrm{Al} / \mathrm{SiC} / \mathrm{Gr}$, conducting a non-lubricating wear test, mainly on the tribe with a pin on the disk, the following conditions were used: load from $10 \mathrm{~N}$ to $60 \mathrm{~N}$, slip speed from $1 \mathrm{~m} / \mathrm{s}$ to $3 \mathrm{~m} / \mathrm{s}$, sliding distance up to 
$1000 \mathrm{~m}$. The particle size in the base alloy varies from $\mathrm{nm}$ for $\mathrm{SiC}$ to $\mathrm{mm}$ for $\mathrm{Gr}$.

The influence of the load on the wear rate of the $\mathrm{Al} / \mathrm{SiC} / \mathrm{Gr}$ composite with a different mass percentage of SiC particles, in the presence of graphite, is shown in Fig.12 [44]. Based on the diagram in Fig.10, it can be concluded that the wear intensity increases with increasing load. Increasing the share of $\mathrm{SiC}$ particles in the volume of the hybrid composite, on the other hand, causes a decrease in the wear intensity, as the hardness of the composite material increases. The slip speed increases, for the same experimental conditions (the same load and sliding distances), it causes a decrease in wear intensity.

The influence of the load on the coefficient of friction of the composite $\mathrm{Al} / \mathrm{SiC} / \mathrm{Gr}$, with different mass percentage of $\mathrm{SiC}$ particles, is shown in Fig.11 [44]. In addition, the influence of the load on the coefficient of friction of the $\mathrm{Al} / \mathrm{SiC} / \mathrm{Gr}$ composite with different percentages of particle mass $\mathrm{Gr}$ particles and fixed $5 \% \mathrm{SiC}$ in the total mass of the composite is shown, as shown in the Fig.12 [44].

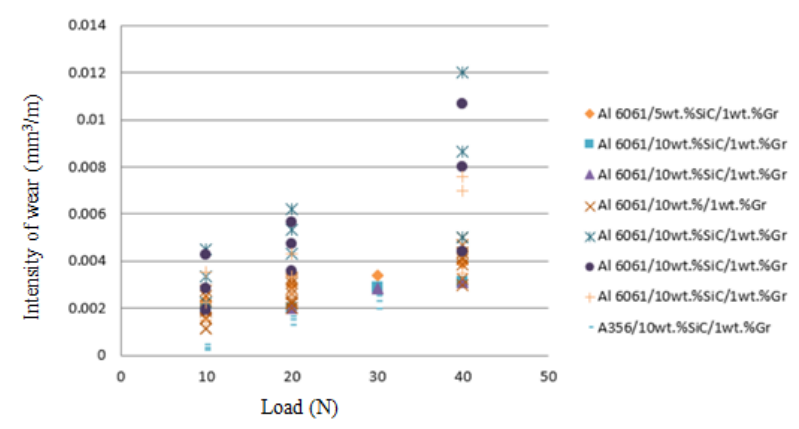

Fig. 10. The influence of the load on the wear rate of the $\mathrm{Al} / \mathrm{SiC} / \mathrm{Gr}$ composite with different percentages $\mathrm{SiC}[44]$

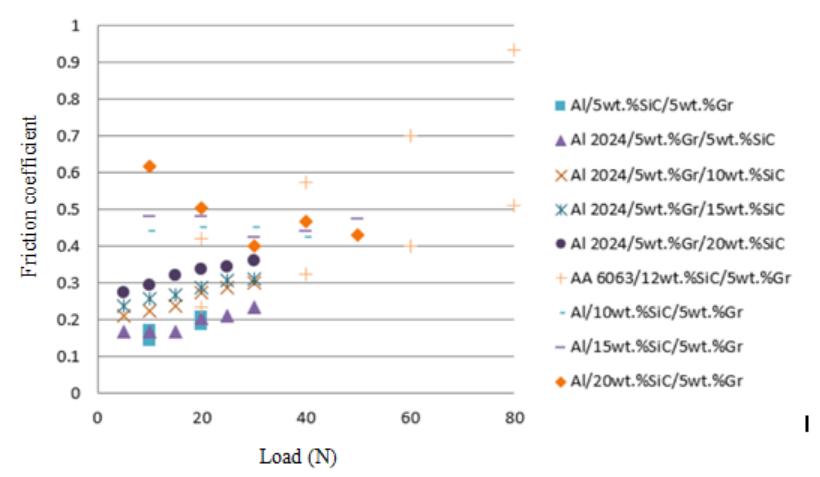

Fig. 11. The influence of the load on the coefficient of friction of the composite $\mathrm{Al} / \mathrm{SiC} / \mathrm{Gr}$, with different mass percentage of $\mathrm{SiC}$ particles [44]

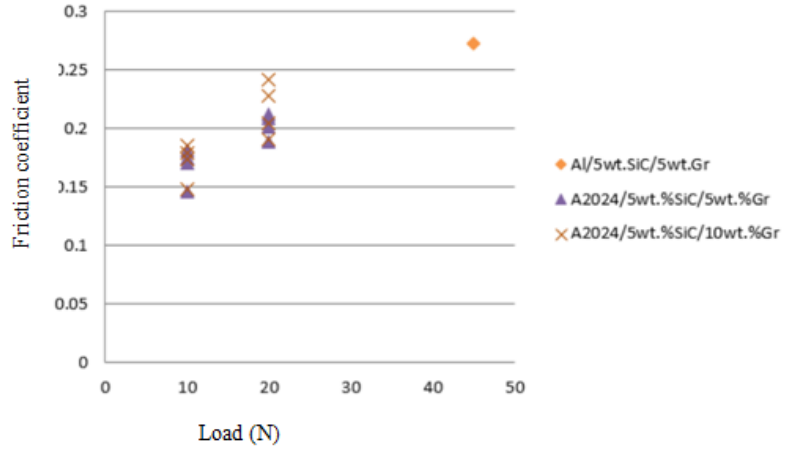

Fig. 12. Effect of the load on the coefficient of friction of the $\mathrm{Al} / \mathrm{SiC} / \mathrm{Gr}$ composite with different percentages of the particle mass $\mathrm{Gr}$ and the fixed $5 \% \mathrm{SiC}$ in the total mass of the composite [44]

\section{CONCLUSION}

Through the chapters of this, it has been shown that aluminum alloys, due to their very good characteristics, are widely used in the construction of various technical systems, and especially motor vehicles. The classic casting method of metal and metal alloys can be successfully used for the production of composites based on aluminum with the desired properties. The reinforcement of aluminum and its alloys with ceramic particles showed a significant improvement in mechanical properties. Adding aluminum to $\mathrm{SiC}, \mathrm{B} 4 \mathrm{C}$ and similar particles improves hardness, degree of utilization, more efficient power transfer, tensile strength. Adding graphite in aluminum increases the strength and elasticity of the material, but reduces the hardness. It also leads to a reduction in the friction coefficient from the aspect of tribological characteristics. Organic additions to aluminum alloys caused a significant increase in the mechanical properties of the formed composites. However, significant progress in tribological traits has not yet been achieved in this area. This provides the possibility for further research in this field.

\section{REFERENCES}

[1] M. Babić, B. Stojanović, S. Mitrović, I. Bobić, N. Miloradović, M. Pantić, D. Džunić, Wear Properties of A356/10SiC/1Gr Hybrid Composites in Lubricated Sliding Conditions. Tribology in Industry, 35 (2), 2013: 148-154.

[2] S. Veličković, B. Stojanović, M. Babić, Optimization of tribological properties of aluminum hybrid composites using Taguchi design. J. Compos. Mater., Sept, 2016. 
https://doi.org/10.1177/0021998316672294

[3] B. Stojanović, L. Ivanović, Application Of Aluminium Hybrid Composites In Automotive Industry. Teh. Vjesn., 22 (1), 2015: 247-251.

https://doi.org/10.17559/TV-20130905094303

[4] B. Stojanovic, M. Babic, S. Mitrovic, A. Vencl, N. Miloradovic, M. Pantic, Tribological characteristics of aluminium hybrid composites reinforced with silicon carbide and graphite. A review, J Balk Tribol Assoc. 19 (1), 2013: 83-96.

[5] A. Skulic, M. Bukvić, Tribological Properties of Piston-Cylinder Set in Internal Combustion Engines. Applied Engineering Letters, 1 (1), 2016: 29-33.

[6] B. Stojanovic, J. Glisović, Automotive Engine Materials. Reference Module in Materials Science and Materials Engineering. Elsevier, 2016: 1-9.

[7] I. Epler, V. Sokolovic, M. Milenkov, M. Bukvić, Application of LEAN tools for Improved Effectiveness in Maintenance of Technical Systems For Special Purposes. Eksploatacja i Niezawodnosc - Maintenance and Reliability, 19 (4), 2017: 616-625.

[8] M. Bukvić, B. Stojanović, S. Milojević, Models And Simulations Of Transmission Of Hybrid And Electric Vehicles. Mobility \& Vehicle Mechanics (MVM), 43 (2), 2017: 3-12.

https://doi.org/Doi 10.24874/mvm.2017.43.02.01

[9] R. Janjić, M. Bukvić, B. Stojanović, Problems of production, use and recycling of motor vehicles. XVIII YUCORR International Conference, 12-15 April, 2016, Tara Mountain, Serbia, pp.405-411.

[10] M. Bukvić, B. Stojanović, Ivanović, L., Milojevic, S., Recycling of the Hybrid And Electric Vehicles. Acta technica corviniensis Bulletin of Engineering, 10 (3), 2017: 107-114.

[11] T. P. Hovorun, K. V. Berladir, V. I. Pererva, S. G. Rudenko, A. I. Martynov, Modern materials for automotive industry. Journal of Engineering Sciences, 40 (2), 2017: F8-F18.

https://doi.org/10.21272/jes.2017.4(2).f8

[12] M. K. Surappa, Aluminium matrix composites: Challenges and opportunities. SADHANA, 28 (1-2), 2003: 319-334.

https://doi.org/10.1007/BF02717141

[13] Iz chego delayut kuzova avtomobiley?

http://amastercar.ru/articles/body of car $3 . \mathrm{shtml}$ (Accessed 20.09.2016).

[14] A. A. Mityaev, I. P. Volchok, R. A. Frolov, K. N. Loza, O. V. Gnatenko, V. V. Lukinov, Kompleksnoe modyfytsyrovanye vtorychnykh sylumynov [Complex modification of secondary silumines]. Nauka ta prohrestransportu. Bulletin of Dnipropetrovsk, National university of railway transport, 54 (6), 2014: 87-96. (In Russian)

[15] I. O. Vakulenko, Yu. L. Nadiezhdin, V. A. Sokyrko, I. P. Volchok, A. A. Mitiaiev, Electric pulse treatment of welded joint of aluminium alloy. Nauka ta prohres transportu. Bulletin of Dnipropetrovsk, National university of railway transport, 46 (4), 2013: 73-82. (In Russian)

[16] S. Pietrowski, G. Gumienny, B. Pisarek, R. Wladysiak, Kontrola produkcji wysokojakosciowych stopow odlewniczych metoda ATD, Archiwum technologii maszyn i automatyzacji, 24 (3), 2004: 131-144 (In Poland)

[17] X. Tian, A. Zhu, J. Wei, R. Han, Preparation and Forming Technology of Particle Reinforced Aluminum Matrix Composites. Materials Science: Advanced Composite Materials, 1 (1), 2017: 1-9.

[18] I. P. Volchok, O. A. Mitiaiev, A. Ye. Ostrovska, O. L. Skuibida, Modyfikator aliuminiievykh splaviv [Modifier of aluminium alloys]. Patent UA, No. u200902454, 2009.

[19] S. Belikov, I. Volchok, O. Mitiaiev, The nanomodifier of aluminium alloys. Aims for future of engineering science, 2006, pp.191193.

[20] N. V. Shyrokobokova, O. A Mitiaiev, et al., Rafinuvalno-modyfikuvalnyi kompleks dlia aliuminiievykh splaviv [Refin-ing and modifying complex for aluminium alloys]. Patent UA, No. u201112705, 2012.

[21] A. K. Telang, A. Rehman, G. Dixit, S. Das, Alternate materials in automobile brake disc applications with emphasis on Al composites a technical review. Journal of Engineering Research and Studies, 1 (1), 2010: 35-46.

[22] W.H. Hunt, D.B. Miracle, Automotive applications of metal matrix composites, D.B. Miracle, S.L. Donaldson (Eds.). ASM Handbook: Composites, Vol.21, ASM International, Materials Park, Ohio, pp.10291032, 2001.

[23] P.K. Rohatgi, S. Ray, and Y. Liu, Tribological Properties of Metal Matrix Graphite Particle Composites. International Materials Reviews, 37 (1), 2013: 129-152.

https://doi.org/10.1179/imr.1992.37.1.129

[24] P.K. Rohatgi, et al., Solidification during Casting of Metal-Matrix Composites, Invited 
paper. ASM Handbook, Vol.15, ASM International, 2008: 390-397.

https://doi.org/10.1361/asmhba0005227

[25] E. Korin, R. Reshef, D. Tshernichovesky, E. Sher, Reducing cold-start emission from internal combustion engines by means of thermal energy storage sys-tem. Proceedings of the Institution of Mechanical Engineers, Part D: Journal of Automobile Engineering, 213 (6), 1999: 575-583.

https://doi.org/10.1243/0954407991527116

[26] M. Kestursatya, J.K. Kim, P.K. Rohatgi, Friction and Wear Behavior of Centrifugally Cast Lead Free Copper Alloy Containing Graphite Particles. Metallurgical and Materials Trans., 32A (8), 2001: 2115-2125.

[27] A. Macke, B.F. Schultz, P.K. Rohatgi, Metal Matrix Composites Offer the Automotive Industry an Opportunity to Reduce Vehicle Weight, Improve Performance. Advanced Materials and Processe, March, 2012.

[28] Q. Jun, A. Linan, P.J. Blau, Sliding Friction and Wear Characteristics of Al203-Al Nanocomposites. Proceedings of IJTC2006 STLE/ASME International Joint Tribology Conference, Paper No. IJTC2006-12326, 2006: 59-60.

https://doi.org/doi:10.1115/IJTC2006-12326

[29] B.F. Schultz, J.B. Ferguson, P.K. Rohatgi, Microstruc-ture and Hardness of Al2O3 Nanoparticle Reinforced Al-Mg Composites Fabricated by Reactive Wetting and Stir Mixing. Mat. Sci. and Eng.: A, 530 (-), 2011: 87-97.

https://doi.org/10.1016/i.msea.2011.09.042

[30] P.K. Rohatgi and D. Weiss, Casting of Aluminum-Fly Ash Composites for Automotive Applications. SAE International, Technical Paper No. 2003-01-0825, 2003.

https://doi.org/10.4271/2003-01-0825

[31] G. Withers and P.D.W. Tilakaratna, Performance Evaluation of ULTALITE $^{\circledR}$ Low Cost Aluminum Metal Matrix Com-posite Based Brake Drums. SAE International, Technical Paper No. 2005-01-3936,2005.

https://doi.org/10.4271/2005-01-3936

[32] W. Maddever and S. Guinehut, Use of Aluminum Foam to Increase Crash Box Efficiency. SAE International, Tehcnical Paper No.2005-01-0704,2005.

https://doi.org/10.4271/2005-01-0704

[33] P.K. Rohatgi, et al., Synthesis of Aluminum-Fly Ash Particulate Composite by Pressure
Infiltration Technique. Mat. Sci. and Engrg., A, 244 (-), 1998: 22-30.

https://doi.org/10.1016/S0921-5093(97)00822-8

[34] S.V. Kamat, S.P. Hirth, R.M. Mehrabin, Mechanical properties of particulatereinforced aluminum-matrix composites. Acta Metallurgy, 37 (9), 1989: 2395-2402.

[35] K.L. Tee, L. Lu, M.O. Lai, Wear performance of in-situ Al-TiB2 composite. Wear, 240 (-), 2000: 5-64.

https://doi.org/10.1016/S0043-1648(00)00337-9

[36] K.K. Alaneme, B.O. Ademilua, M.O. Bodunrin, Mechanical Properties and Corrosion Behaviour of Aluminium Hybrid Composites Reinforced with Silicon Carbide and Bamboo Leaf Ash, Tribology in Industry, 35 (1), 2013: 25-35.

[37] A.N. Abdel-Azim, M.A. Kassem, Z.M. ElBaradie, M. Waly, 2002, Structure and properties of short alumina fibre reinforced AlSi18CuNi produced by stir casting, Materials Letters, 56 (6), 2002: 963-969.

https://doi.org/10.1016/S0167-577X(02)00647-X

[38] B. Stojanovic, M. Babic, S. Velickovic, J. Blagojevic, Optimization of wear behaviour in aluminium hybrid composites using Taguchi method. $14^{\text {th }}$ International Conference on Tribology "SERBIATRIB 15", 13-15 May, 2015, Belgrade, Serbia, pp.81-86.

[39] S. Amirkhanlou, B. Niroumand, Synthesis and characterization of 356-SiCp composites by stir casting and compocasting methods, Trans. Nonferrous Met. Soc. China, 20 (Suppl.3) 2010: s788-s793.

https://doi.org/10.1016/S1003-6326(10)60582-1

[40] Hai Su, Wenli Gao, Zhaohui Feng, Zheng Lu, Processing, microstructure and tensile properties of nano-sized $\mathrm{Al} 2 \mathrm{O} 3$ particle reinforced aluminium matrix composites. Materials and Design, 36 (-), 2012: 590-596.

https://doi.org/10.1016/j.matdes.2011.11.064

[41] K. Kalaiselvan, N. Murugan, Siva Parameswaran, Production and characterization of AA6061-B4C stir cast composite. Materials and Design, 32 (-), 2011: 4004-4009.

https://doi.org/10.1016/j.matdes.2011.03.018

[42] S. Wilson, A.T. Alpas, Effect of temperature on the sliding wear performance of Al alloys and A1 matrix composites. Wear, 196 (1-2), 1996: 270-278.

https://doi.org/10.1016/0043-1648(96)06923-2 
[43] K.L. Tee, L. Lu, M.O. Lai, Wear performance of in-situ Al-TiB2 composite. Wear, 240 (1-2), 2000: 59-64.

https://doi.org/10.1016/S0043-1648(00)00337-9

[44] S. Veličković, S. Limadinović, B. Stojanović, R. Nikolić, B. Hadzima, D. Arsić, J. Meško,
Tribological characteristics of $\mathrm{Al} / \mathrm{SiC} / \mathrm{Gr}$ hybrid composites. $2^{\text {th }}$ International Conference Quality Production Improvement - QPI 2018, MATEC Web of Conferences, Vol.183, 2018. https://doi.org/10.1051/matecconf/201818302001 